\title{
ASSESSMENT OF KNOWLEDGE, ATTITUDE AND PRACTICES REGARDING DENGUE FEVER AMONG ADULT POPULATION OF DISTRICT DIR LOWER, KHYBER PAKHTUNKHWA, PAKISTAN
}

\author{
Aminullah', Soaib Ali Hassan ${ }^{2}$, Ashfaq Ahmed Khawaja Khail ${ }^{3}$, Abdul Waris ${ }^{4}$, Gul Alam $^{5}$ and Salahuddin \\ Khan Marwat ${ }^{6}$
}

${ }^{1}$ Nurse, Health Department, Khyber Pakhtunkhwa.

${ }^{2}$ Assistant Professor, Health Department Balochistan.

${ }^{3}$ Medical Entomologist, Health Department, Khyber Pakhtunkhwa.

${ }^{4}$ Pharmacist, Health Department, Balochistan.

${ }^{5}$ Medical Entomologist, Global Fund.

Correspondence: Aminullah. Contact No. 0333-2096087,E-mail: draminhsa@yahoo.com

\begin{abstract}
Background: Dengue is a major public-health concern throughout globe especially tropical and sub-tropical regions. Dengue fever is transmitted by bite of female mosquito caused by human viral pathogen that belongs to the genus Flavivirus of the family Flaviviridae. World Health Organization (WHO) estimates that 50-100 million dengue infections occur each year and that almost half the world's population lives in countries where dengue is endemic. The first confirmed dengue hemorrhagic fever outbreak in Pakistan occurred in 1994. Since then, epidemics of dengue fever have been reported in the region with increasing frequency and expanding geographic distribution.

Objectives: To assess the knowledge, attitudes and preventive practices regarding dengue fever among adult population.

Methods: This study was a Cross sectional descriptive survey conducted among adult population in Union council Ouch and Chakdarah district Dir Lower, KPK province Pakistan. The study was collected in the months of October to December 2015. Sample size was calculated through sample size formula calculation and total of 419 subjects including male and females were interviewed using a pre-tested structured questionnaire selected through simple random sampling technique.

Results: Majority of study population were males (79.3\%) and living in houses made of bricks (68.3\%). Majority of population was unaware regarding dengue fever transmission, its sign and symptoms and treatment $(58.9 \%)$. Respondents' main source of information was TV and radio. The study participants consider dengue as a fatal disease and the preventive practices from mosquito bite were recorded as, full clothing $(24.4 \%)$ followed by use of repellents $(10 \%)$. Around half of the respondents were using bed net for dengue prevention in which $36 \%$ got it from various NGOs working in the district.
\end{abstract}

Conclusion: There is lack of knowledge about dengue fever among the communities. Preventive practices can be improved by increasing knowledge and its translation into sustainable practices.

Keywords: Knowledge, preventive practices, mosquito borne diseases, low and middle income country.

\section{Introduction}

Dengue is a major public-health concern throughout globe especially tropical and sub-tropical regions.(1,2) Dengue fever is transmitted by bite of female mosquito caused by human viral pathogen that belongs to the genus Flavivirus of the family Flaviviridae (single-strand, non-segmented RNA viruses). The dengue virus is divided into four serotypes (DEN-1, DEN-2, DEN-3, and DEN-4). (3) Dengue fever predominantly occurs in Southeast Asia, Americas, Africa and the Caribbean Islands. There has been a gradual global upsurge in the number of dengue cases in the last decade. (4) Dengue is transmitted in humans by two species of Aedes mosquitoes namely, Aedes Aegypti (principal vector) and Aedes Albopictus. There are three main forms of dengue disease, dengue fever and the more severe dengue hemorrhagic fever (DHF) and Dengue Sock Syndrome (DSS). (4)

Dengue causes more illness and death than any other Arbovirus. Worldwide, there are approximately 2.5 billion people at risk of infection, and the World Health Organization (WHO) estimates that there are about 50 to 100 million cases per year (5). Although dengue-like symptoms had been reported earlier, the first known pandemic of dengue-like illness began in 1779 (6). Recently dengue out breaks has been reported from Pakistan, Saudi Arabia, Sudan and Yemen, 2005-2006. (7) 
The first confirmed dengue hemorrhagic fever outbreak in Pakistan occurred in 1994. $(6,7)$ In southern Pakistan the epidemic was present for two consecutive years. During 2005-2006 a large number of DHF reported from Karachi. More than 3,640 patients with sign and symptoms of dengue fever were admitted to several referral hospitals in the country. Outbreak of dengue has been reported from Provence Khyber Pakhtun Khawa during 2007, 2008and 2009 (8). In 2011 when dengue epidemic occurred in Lahore, dengue got the importance of great Public health problem in Pakistan. (9) Since then the expansion of dengue infections with increasing frequency and severity has been reported from all over Pakistan. In 2013, a worse epidemic occurred in district Swat, KPK with total 9,038 confirmed cases and 67 deaths (10). Recently in 2015 dengue cases occurred in different cities of both Provinces Khyber Pakhtun Khawa and Punjab. (11)

\section{Methodology}

This Cross sectional descriptive study was conducted in district Dir, KPK province Pakistan. Adult population (15 to 60 years of age) including male and female residing in Union councils Ouch and Chakdarah district Dir Lower. A total sample size of 419 was selected sample size formula and respondents were selected through simple random sampling technique, considering the total adult population of Union councils Ouch and Chakdarah.

A structured questionnaire was developed with the help of faculty members of Department of Medical Entomology and Disease Vector Control (MEDVC). The developed questionnaire was pre-tested among the adult population of similar characteristics in Union council Talash of district Dir Lower. After getting the responses from the community questionnaire was edited with minor changes and finalized for the survey.

Inclusion criteria for study subject were the adult population including males and females who were permanent residents of Union council Ouch and Chakdarah district Dir lower. Exclusion criteria for the study was that those who do not consented to participate in the study, population below the age of 15 and above 60 years. Permission to conduct the research was obtained from Ethical review Board of Health Services Academy Islamabad and verbal consent was taken from each study participant prior to interview.

The data were collected through a pre-tested structured Questionnaire from 1st October to 31st December, 2015. Data were analyzed through SPSS version 20. The results were categorized as Socio demographic information, Knowledge about Dengue fever, Attitude toward dengue fever and Preventive practices toward Dengue fever. Descriptive statics were presented in the form of Tables, graphs (Bar charts), frequency and percentage. The overall knowledge and attitudes were calculated by taking means for each group; those who scored below mean value were considered as "Poor Level" and scoring above mean were considered as "Good Level" for both knowledge and attitudes.

\section{Results}

Out of 419 questionnaires, 401 were analyzed as 18 refuse to give information. Out of 419,318 respondents were males. $33.7 \%$ respondents $(n=136)$ were in age group of 18 to 30 years, followed by 31 to 40 years of age $(n=128) 196$ of the respondents were married while only 1 and 2 of respondents were divorced and widows respectively. Regarding the highest education attainment level, 36 had postgraduate level of education, 70 of the respondents were graduates, and 54 respondents had passed their S.S.C. and 124 of the respondents were illiterate. About 133 respondents had income between 10,000 to 20,000 PKR and 91 had monthly income above 20000 thousands. $68.3 \%$ of the respondents resided in houses made of bricks. Regarding water source, it was found that more than half of the studied population was using piped water which is $68.6 \%$, about $26.9 \%$ were using water of well and $3.7 \%$ household were using water of stream and only $0.7 \%$ used water from other sources

Knowledge about Dengue fever

Most of the respondents had poor level of knowledge as shown in table 1 below:

Table 1: Overall level of Knowledge regarding Dengue fever

\begin{tabular}{|c|c|c|}
\hline Level of Knowledge & Frequency & Percent \\
\hline Poor & 236 & 58.9 \\
\hline Good & 165 & 41.1 \\
\hline Total & 401 & 100 \\
\hline
\end{tabular}

Nearly, all (93.5\%) of the respondents had heard about the dengue fever. Regarding dengue transmission, most $(80.5 \%)$ of the respondents knew that dengue was a contagious disease. Just less than two third $(60.1 \%)$ of the respondents, knew about the symptoms of dengue fever. Regarding treatment of dengue fever, most $(90.5 \%)$ of the respondents said that dengue was a treatable. As for as season of dengue was concerned, most $(89.3 \%)$ of the respondents had the knowledge that rainy days in the Summer was usually the favorable time for dengue fever.

About two third (66.6\%)of the respondents knew that dengue spread through mosquito bite and less than one fourth $(17.2 \%)$ respondents knew that drinking dirty water was responsible for the disease. About a half $(52.4 \%)$ of the respondent claimed that they had seen the dengue mosquito. About two third (68.6\%) of the respondents told that all age group people were susceptible to mosquito bite. Multiple responses were obtained for the knowledge about the biting time of dengue mosquito. Regarding the biting time of the mosquito, only about one third (36.4\%) of the responses were correctly about dawn and dusk times of biting by the mosquito. Rest were about at the time of sun rise 
(16.5\%), of the night time biting (31.2\%), of the day time biting $(5.5 \%)$, and not knowing about the biting time of mosquito $(10.5 \%)$. A little less than half $(40.6 \%)$ of the respondents did not know about the breeding places of the dengue mosquito. More than half of the respondents said that TV/ Radio was a useful source of spreading information regarding dengue, while a few $(13.5 \%)$ had information about dengue from a newspaper.

\section{Attitude towards Dengue Fever}

About half of the respondents $(50.6 \%)$ had a good level of attitude regarding dengue fever (table 2 ).

Table 2: Overall level of Attitude regarding Dengue Fever

\begin{tabular}{|c|c|c|}
\hline Level of Attitude & Frequency & Percent \\
\hline Poor & 198 & 49.4 \\
\hline Good & 203 & 50.6 \\
\hline Total & 401 & 100 \\
\hline
\end{tabular}

About two third $(61.1 \%)$ of the respondents considered dengue as a fatal disease. About the availability of the vaccine for dengue fever, nearly two third of the respondents said that there was no vaccine available for the dengue fever. About three fourth of the respondents thought that fever was preventable. About three fourth $(73.6 \%)$ of the respondent considered dengue as a more dangerous disease than malaria.

\section{Practices toward dengue fever}

Respondents were asked regarding their practices to prevent mosquito bite. A few $(9.7 \%)$ of the respondents considered indoor residual spray (IRS) as the best preventive measure from mosquito bite, about one fourth $(24 \%)$ responded that the bed nets were the better option, another one fourth (24.4\%) used full clothing to prevent mosquito bite, while another a few of them $(10.0 \%)$ used repellents to repel mosquito. Among those all responded, about half $(53.6 \%)$ of them never used bed nets for prevention of mosquito bite. Most (81.5\%) respondents said that they visited a doctor for treatment of fever while a few $(4.2 \%)$ got treatment from hakims and a few more (11.2\%) visited religious healer for the treatment (table 3 ).
Table 3: Practices of respondents on prevention of Dengue Fever ( $\mathrm{N}=401)$

\begin{tabular}{|c|c|c|c|c|}
\hline $\begin{array}{l}\text { S. } \\
\text { No }\end{array}$ & Variable & Responses & Frequency & Percentage \\
\hline \multirow{7}{*}{1} & \multirow{7}{*}{$\begin{array}{l}\text { Prevent Mosquito } \\
\text { Bite }\end{array}$} & Insect spray & 39 & 9.7 \\
\hline & & Bed-net & 24 & 6 \\
\hline & & Full clothing & 98 & 24.4 \\
\hline & & Door/window Screening & 11 & 2.7 \\
\hline & & Repellent & 40 & 10 \\
\hline & & None & 135 & 33.7 \\
\hline & & Other & 54 & 13.5 \\
\hline \multirow{4}{*}{2} & \multirow{4}{*}{$\begin{array}{l}\text { Elimination of } \\
\text { Mosquito Breeding }\end{array}$} & Cover water & 257 & 64.1 \\
\hline & & Prevent stagnation & 68 & 17 \\
\hline & & Removing vegetation & 25 & 6.2 \\
\hline & & Other & 51 & 12.7 \\
\hline \multirow{4}{*}{3} & \multirow{4}{*}{$\begin{array}{l}\text { Get Dengue } \\
\text { Treatment }\end{array}$} & Doctor & 327 & 81.5 \\
\hline & & \begin{tabular}{|l|} 
Hakims \\
\end{tabular} & 17 & 4.2 \\
\hline & & Maulana & 45 & 11.2 \\
\hline & & Other & 12 & 3 \\
\hline \multirow{2}{*}{4} & \multirow{2}{*}{$\begin{array}{l}\text { Have you ever used } \\
\text { Bed-net }\end{array}$} & Yes & 186 & 46.4 \\
\hline & & No & 215 & 53.6 \\
\hline
\end{tabular}

Of those who were using bed nets; just above one fourth of them $(28 \%)$ purchased bed nets by their own, while a half of all of them (55\%) got bed nets from different NGOs and only a few (15got them from the government.

\section{Source of recieving Bed-net}

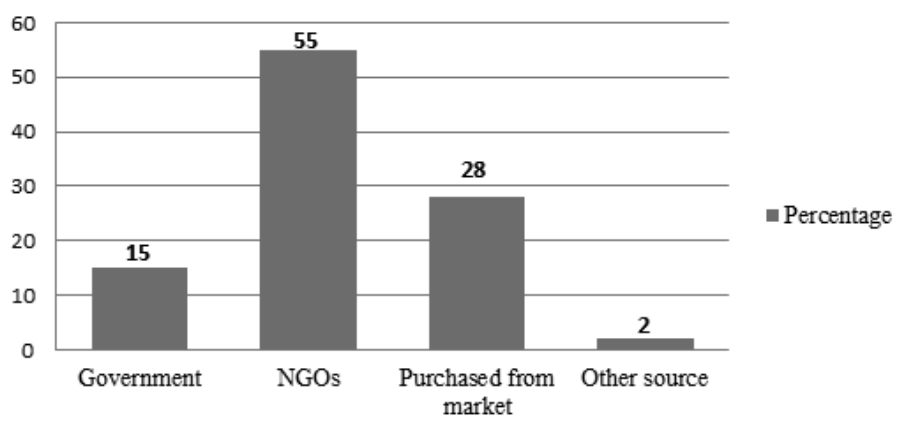

\section{Figure 1 Source of receiving bed-net}

Discussion

The present study was conducted in adult population for assessing gaps in knowledge, attitude and practices regarding dengue fever. The knowledge about dengue fever symptom, its treatment, and its transmission was found low. Nearly two third $(66.6 \%)$ knew that dengue could be transmitted through mosquito bite. These finding of study are very close with the study conducted by Hafez et al in 2012. (12) Also similar results were published in a KAP study conducted in seven government hospital in Ang-Thong province of Thailand during 1999 (13).

Respondents' attitude toward dengue fever and it being more dangerous than malaria was good. Though our findings were not similar to the KAP study conducted among household in a peri urban community of PakNgum district of Vientiane capital, Laos (16), we assume that as the dengue treatment was not yet readily available as compared to malaria, contrary to the 
Vietnam study, people had more fear of dengue than malaria in our settings. The community preventive practices regarding removing the breeding site of dengue vector revealed that the two third of the population considered covering of clean water was the best method to remove the breeding site of vector. AKAP study conducted in two sub-districts of Kamphaeng Phet province, Thailand, revealed that reduction practices were used only when people experienced any mosquito nuisance problem (17). One reason for poor preventive practices could be the low income and socio-economic status of the study population. Because of the high prices of daily edibles and utility bills, it could be difficult for a common man to purchase bed net, repellent or insecticides. Also may be due to the geo-political and security situation, the national and international NGOs hesitated to work for dengue in our study area.

Conclusion:

The knowledge about dengue fever, its mode of transmission, its sign and symptoms and treatment were partially known to the study respondents. The best information source was found to be through TV and Radio. The respondents considered dengue as a fatal disease and believed it could be prevented through different techniques and they consider dengue as more fatal than malaria. The best preventive practice from mosquito bite was the insecticide sprays, followed by bed net, full clothing and door or window screening.

Provision of the bed nets may be scaled-up by the provincial malaria control programme. Further qualitative research in the community may be conducted to probe the factors related to the current attitudes and practices of communities for a sustainable behavior and to develop and implement effective dengue prevention and control programs.

\section{References}

1. Jahan F. Dengue Fever (DF) in Pakistan. Asia Pac Fam Med 2011 10(1): 1.

2. World Health Organization, Western Pacific Region. Dengue fact sheet 2014 http://www.wpro.who.int/mediacentre/factsheet s/fs 09032012 Dengue/en/

3. World Health Organization. Dengue: Guidelines for diagnosis, treatment, prevention and control. New Edition. WHO \& Special Programme for Research and Training in Tropical Diseases (TDR). 2009.

4. Dengue Fever World Health Organization Fact Sheet No.117. 2015.http://www.who.int/ mediacentre/factsheets/fs117/en/

5. Qureshi JA, Notta NJ, Salahuddin N, Zaman V, Khan JA. An epidemic of dengue fever in Karachi: Associated clinical manifestations. J Pak Med Assoc 1997;47: 178-81.

6. Chan YC, Salahuddin NI, Khan J, Tan HC, Seah $\mathrm{CL}$, Li J, et al. Dengue haemorrhagic fever outbreak in Karachi, Pakistan, 1994. Trans R
Soc Trop Med Hyg1995; 89: 619-2.

7. Hakim ST, Saleem M, Nadeem SG. An Experience with Dengue in Pakistan: An Expanding Problem. Ibnosina J Med BS 2011; 3(1): 3-8.

8. Qadir S, Ahmad I. Knowledge, Attitude and Practices about Dengue fever among local population. Gomal J Med Scienc. April-June 2015, 13(2). 87-90

9. Humayoun MA, Waseem T, Jawa AA, Hashmi MS, Akram J. Multiple dengue serotypes and high frequency of dengue hemorrhagic fever at two tertiary care hospitals in Lahore during the 2008 dengue virus outbreak in Punjab, Pakistan. Int J Infect Dis 2010; 14S3:e54-e59.

10. Khan H. Wake-up: Dengue epidemic is at the door step. Gomal J Med Sci 2011; 9: 143-4.

11. World Health Organization. Support to Pakistan on dengue fever. Pakistan statistics 2015 http://www.emro.who.int/pak/pakistaninfocus/world-health-day.html

12. Hafez et al, Knowledge and Attitude of public toward dengue control in rural and urban area of Punjab. 2012. Pakistan J. Zool., Vol 44 (1) pp. 15-20

13. Kittigul L, Suankeow K, Sujirarat D, Yoksan S. Dengue hemorrhagic fever: knowledge, attitude and practice in Ang Thong Province, Thailand. Southeast Asian J Trop Med Public Health. 2003 Jun;34(2):385-92.

14. Matta S, Bhalla S, Singh D, Rasania SK, Singh S .Knowledge, Attitude and Practice (KAP) on dengue fever: a hospital based study. Indian J of Comm. Medicine July-September, 2006. 31(3). 21-24

15. Mirza H, Raza H, Bashir R, Knowledge, Attitude \& Perception of Dengue among First Year Medical Students at Lahore. Pakistan J of Med. And Health Sciences (online) Jan-March 2013. Available at http://pjmhsonline.com/ JanMar2013/knowledge_attitude_and_percepti on_of_dengue.htsm

16. Mayfong M, Wanyuan C, Sounthone T. Dengue in peri-urban Pak-Ngum district, Vientiane capital of Laos: a community survey on knowledge, attitudes and practices. BMC Public Health. 2013; 13: 434. Available at http://www.ncbi.nlm.nih.gov/pmc/articles/PMC3 645963/

17. Koenraadt CJ, Tuiten W, Sithiprasasna R, Kijchalao. Dengue knowledge and practices and their impact on Aedes aegypti populations in Kamphaeng Phet, Thailand. Am J Trops Med Hyg. 2006 Apr;74(4):692-700. Available at http://www.ncbi.nlm.nih.gov/pubmed/16607007 